Paul Sturges

\title{
What is this absence called transparency?
}

\begin{abstract}
:
Campaigners against corruption advocate transparency as a fundamental condition for its prevention. Transparency in itself is not the most important thing: it is the accountability that it makes possible. Transparency itself is, in fact, a metaphor based on the ability of light to pass through a solid, but transparent, medium and reveal what is on the other side. In practice it allows the revelation of what otherwise might have been concealed, and it is applied in a social context to the revelation of human activity in which there is a valid public interest. It can be applied to all of those who hold power and responsibility, whether that is political or economic. More accurate definition of the term, including distinctions between open governance, procedural transparency, radical transparency, and systemic or total transparency is important. Various ways in which an observer can make use of transparency to scrutinise the activity of others, including freedom of information laws, accounting and audit systems, and the protection of public interest disclosure (whistleblowing) also need to be distinguished from each other.
\end{abstract}

\section{Agenda}

Introduction. 222

Accountability 222

From the sublime to the ridiculous 223

Definitions..... 224

Difficulties with the definition 225

Types of transparency 225

Related terms 226

Conclusion

Author:

Prof. Paul Sturges:

- Department of Information Science, Loughborough University, Leicestershire, LE11 3TU, UK

- 正 + 441509 223069, $\square$ r.p.sturges@lboro.ac.uk, http://www.lboro.ac.uk/departments/dis/people/psturges.html

- Relevant publications:

- The Quiet Struggle: Information and Libraries for the People of Africa. With Richard Neill. 2nd ed. London: Mansell 1998, 244 p. 


\author{
A man that looks on glass, \\ On it may stay his eye \\ Or if he pleaseth, though it pass \\ And then the heavens espy. \\ George Herbert (1593-1633)
}

\section{Introduction}

Transparency is a slightly curious concept, in that it is concerned with an absence: the absence of concealment. In that concealment permits corruption, transparency as the absence of concealment is a positive and important concept. A word or two on the significance of corruption provides a suitable introduction to the discussion of transparency. Corruption is universal and the misgovernment that it brings with it is almost as widespread. Wherever there are transactions that offer the opportunity for personal advantage or profit someone, somewhere will take advantage of that opportunity. Corruption can be such a part of life that citizens of a badly corrupt country may scarcely imagine that it can be reduced or eliminated. Nevertheless, condemnation of corruption is a universal theme of conversation and political debate worldwide. People long for an honest, predictable, corruption-free world. They also tend to despair that it can ever be achieved. The example of one country, Kenya, chosen almost at random, can illustrate this.

For reasons that may not seem wholly obvious, British politicians and diplomats have spoken out unusually sharply about corruption in Kenya in recent years. On an official visit in 2006, the UK Minister of State for Foreign Affairs said that:

Kenyans can be bought: from the person who works at the docks in Mombasa up to the government. You can buy off politicians; you can buy off policemen. The weakness has been recognised by drug traffickers and probably by terrorists too. (Rice, 2006)

Two years earlier, the UK High Commissioner in Nairobi, Edward Clay, had accused the Kenyan government of wholesale corruption.

Evidently the practitioners now in government have the arrogance, greed and perhaps a sense of panic to lead them to eat like gluttons. They may expect that we shall not see, or will forgive them, a bit of gluttony. But they can hardly expect us not to care when their gluttony causes them to vomit all over our shoes.' (Clay, 2004)
Britain, though not free of high level corruption itself, clearly fears the corrosive effects on trade and international stability of an excessively corrupt regime in Kenya. It had hopes that the problem in Kenya would be reduced with the election of the new government of President Mwai Kibaki in 2003 on anti corruption manifesto. However, the notorious corruption that pervaded every aspect of the country's life under his predecessor Daniel arap Moi was certainly not eliminated, and probably little reduced. It continues not only to effect the nation's international standing, but to make the lives of individual Kenyans even more painfully difficult than they need to be. The question that this raises is, if even politicians who are pledged to cleanse the system cannot resist temptation themselves and leave the problem unsolved, can anything be done at all? Are we condemned to accept corruption, however much we hate it?

This is where the concept of transparency comes into the equation. The introduction of transparency into governance is almost universally offered as the key to eliminating corruption, usually along with enforcement measures and relevant practical changes in modes of governance. In fact, it can be suggested that it is more than that: transparency is one of the key components of twenty first century governance, business and social organisation, but the use of the word threatens to become clichéd. Transparency has strong positive connotations, but do those who use it always have a clear and full idea of what they mean by it? Anyone who picks up a copy of a good newspaper is almost certain to find at least one reference to transparency somewhere in its pages. The frequency with which the presence or absence of transparency is commented upon, or with which some activity or transaction is described as transparent is too great for us to feel sure that it is always being used consistently. This is not a trivial matter. Transparency is important and it concerns us all in a multitude of ways.

\section{Accountability}

However, it is not actually transparency itself that is the most important thing. Transparency concerns us because it has a purpose. The purpose of transparency is accountability. Accountability is the reason why transparency is introduced into systems of public and corporate governance. Transparency allows examination of the stewardship that is expected of those who own or have the care of resources that are matters of public concern. Transparency is also introduced into what might at first 
seem to be purely private matters because of the need for the public accountability of individuals for certain kinds of actions. Crime is the most obvious example. Nations have systems of criminal law because some conduct (theft, fraud, assault, murder and a host of other offences) by individuals who have no particular public office or status is regarded as not merely damaging to other members of society but to the fabric of the society itself (the 'peace' that the Crown offers to guarantee in Britain, for example). The individual's conduct is open to investigation and revelation in the courts of law for the ultimate purpose of preventing crime. For individuals to be accountable, there must be some kind of transparency regarding what they have done.

For accountability to be effective and fair to those whose conduct it reveals, a well worked-out concept of the public interest is required. The existence of a genuine need to know, generally spoken of as the public interest, is central to the rationale for all aspects of transparency. In a transparent system the emphasis switches from a presumption that the holders of information can decide whether there is a genuine public interest in the disclosure of information, to a presumption that it can be revealed. The exception to this principle applies when it can be shown that it is not actually in the public interest to do so. Decisions on what constitutes the public interest are often a matter that is left to the law courts to decide because of the delicate considerations that need to be balanced in some cases. The courts are presumed to rule on the basis of a balancing of the public need to know against the need of the state, business or even an individual to keep something concealed from public knowledge. The effectiveness of transparency in particular cases depends on how such questions are resolved. However, when we consider transparency generally, it is vital that there is a widely accepted consensus on what forms of transparency are in the public interest and what are not. Furthermore, anyone who uses information, works professionally with information, or is concerned about the role of information in society needs to understand transparency better. (Cox, 2006) In twenty first century society - the information society - this is becoming effectively everyone.

\section{From the sublime to the ridiculous}

At one extreme, transparency can be used as a means to great objectives. The South African Truth and Reconciliation Commission, set up under an Act of Parliament of 1995, was a national transparency exercise aimed at healing the wounds of an exceptionally divided society. Its hearings were to allow the revelation of the truth about what actually happened in the enormous number of cases of human rights violations that had taken place under the apartheid system. The aims were to:

- Allow victims an opportunity to tell of the violations they suffered;

- Grant reparation to victims, provide for their rehabilitation and the restoration of their human and civil dignity;

- Grant amnesty to those who make full disclosure of the politically motivated acts they had committed against others.

This national exercise in catharsis brought a humane end to a period of institutionalised repression. For the oppressed to be able to tell of what they had suffered and to find out from the evidence of the oppressors what had actually happened to friends and family was an enormous release. For white South Africans it was often the first time they had been obliged to contemplate the depths that those who had acted on their behalf had plumbed. South Africa is still a society with problems to solve but after the work of the Truth and Reconciliation Commission it is better armed to solve them

At the same time, what might seem to be another type of exercise in transparency pervades twenty first century life. This is the response of the media to people's interest in the details of the lives of others, for what seems to be the sake of the details themselves. The lives of those who have some form of celebrity have come to be of consuming interest to large numbers of members of the public. This begins because performers of all kinds in the arts and sports, offer a kind of pseudo transparency for selected aspects of their live as part of the process of promoting their careers. The media then take this as licence to reveal as much as they can in addition, using journalists who specialise in celebrity stories, paparazzi photographers, and plots to entrap the subjects of curiosity into revealing more than they might wish. This idle and prurient interest in the lives of celebrities sells newspapers and attracts viewers to television programmes, but it tells us nothing that is actually useful to us. The public response to these types of revelation cannot be regarded as the same thing as a genuine public interest in the sense of a need to know for a purpose.

What is comparatively new is that some members of the public, most of whom have no solid prospect of 
financial or other gain from it, are prepared to offer up a similar kind of exposure. In the past it might have been possible to assume that the desire for privacy would guide people's attitudes towards possible public revelations concerning themselves. Quite to the contrary, the taste for this type of exposure has proved infectious. Otherwise ordinary people queue to offer insights into their lives on TV programmes of the Jerry Springer kind. 'Coat me in chocolate and feed me to the lesbians' sings a character in Jerry Springer: The Opera, a satire on this type of television. In other words, I'll offer almost any kind of public exposure if it gets me the moment of fame that such programmes offer. Candidates for programmes of the Big Brother kind compete desperately to be allowed to subject themselves, their empty minds and sometimes their bodies, to the scrutiny of television audiences whilst they are in some kind of voluntary confinement. None of this is transparency in any valid sense of the word, because it has no serious purpose: it offers no element of accountability because the subjects have nothing of substance that it is in the public interest to reveal.

\section{Definitions}

So, what precisely does the word transparency mean? As with many words, it has several distinct meanings. In scientific terminology transparency means the transmission of electromagnetic rays without distortion, but this is not the way that the word is used in everyday speech. The ordinary, every-day meaning, and the way that dictionaries still usually define the word, is simply the condition of allowing light to pass through a medium such as glass so that clear vision of something on the other side is possible. It is a stronger term than the companion-word translucency, which refers to allowing light to pass through diffusely in a way that does not enable things on the other side to be seen distinctly.

The relevant meaning for our purposes is a metaphor stemming from the word's original meaning of allowing clear vision. This metaphorical transparency is a comparatively new usage that has emerged very strongly during the 1990s. Transparency used in this metaphorical way can be defined as:

The condition in which knowledge of activities that are of public interest is revealed so as to provide the potential for accountability.
This definition is broad enough to accommodate the wide range of ways in which the label of transparency is currently applied. It tells us that transparency is about making knowledge available. It answers the question 'What knowledge?' with the answer that it is knowledge about human activity. It tells us why: because the information is of public interest. It further qualifies that by saying that the intention is to make it possible to hold those concerned to account on the basis of what is revealed. Transparency allows voters knowledge of the actions of politicians so they can choose who they wish to elect. It provides details of the workings of business corporations so that investors can make sound decisions on what to do with their money. It allows illegal conduct to be identified and brought before the public tribunals. It even allows listeners, readers and viewers to work out for themselves how far to trust what they told in print and through the media.

As generally used, the word most usually indicates the way in which the conduct of those who have power, be it political, commercial or some other form, is exposed to the gaze of the rest of the world. The NGO Transparency International expresses this in a direct and practical way, calling transparency,

A principle that allows those affected by administrative decisions, business transactions or charitable work to know not only the basic facts and figures but also the mechanisms and processes. It is the duty of civil servants, managers and trustees to act visibly, predictability and understandably. (Transparency International, 2006)

Defined as above, transparency allows light to fall on matters about which people need to know, but which those directly concerned might wish to remain in darkness. Not everyone who uses the term does so with quite this implication. The current definition is beginning to accommodate the idea that in practice transparency is about voluntary disclosure. A current text aimed at the business community suggests that:

Transparency, as currently defined, is letting the truth be available for others to see if they so choose, or perhaps to look, or have the time, means, and skills to look. This implies a passive posture or motivation on the part of the individual or organisation under consideration. In today's broader public context, however, trans- 
parency is taking on a whole new meaning: active disclosure. (Oliver, 2004, p.3)

The word clearly relates to a shifting and developing concept. However, that is not the only difficulty in pinning down what people mean when they use the word.

\section{Difficulties with the definition}

The word transparency's capacity to provide helpful metaphors threatens to become over-stretched and not all usages even have quite the significance we are discussing here. Sometimes the word is used in ways that are closer to the scientific usage of transparency: transmission without distortion. Thus transparency can be used to describe the way light passes through something (like glass or Perspex) as if there were nothing there. In other words, transparency can actually suggest concealment (of an intervening medium). This is the case in information technology where transparency usually refers to the operation of programs and applications that are not apparent to the user, as when the domain names system resolves authorised domain names into Internet protocol addresses. In this case transparency shields the user from the complexity of the system, rather than reveals it. References to network transparency are common in the literature of computing and they too carry this sense that the user works in an environment where there seem to be no barriers or intervening changes of system. It is important to be aware that this usage contrasts directly to the common tendency to refer to open source applications in computing as transparent. Open source is transparent because one is permitted to see through the surface and examine what is inside (the source code). It is the type of transparency represented by open source that concerns us here, rather than network transparency and other instances of transparency that contrive to make the user unaware, rather than aware, of the functioning of systems.

Some definitions of transparency describe it negatively: they tell us what it is not. This type of definition calls it the opposite condition to concealment and secrecy. Florini (2000, p.13), for instance expresses it precisely thus:

Put simply, transparency is the opposite of secrecy. Secrecy means deliberately hiding your actions; transparency means deliberately revealing them.
This is a pretty effective definition, except for the suggestion that transparency is always deliberately offered. Types of involuntary or imposed transparency undoubtedly exist and will be discussed at several points in the chapters that follow.

Some definitions go further than merely contrasting transparency with secrecy and refer to it as the opposite of privacy. A crudely administered regime of transparency can damage privacy, but this is not usually the ostensible intent behind its introduction. The overwhelming weight of use of the word transparency is not to indicate that it throws light into legitimate privacy, but that it exposes the kind of secrecy that is detrimental to society. In fact the particular value of transparency is its ability to reveal corrupt practices and show citizens how they can limit the damaging effects of corruption in their own lives. Brin (1998, p.334) sums up the relationship between transparency and privacy by saying:

Transparency is not about eliminating privacy. It is about giving us the power to hold accountable those who would violate it.

Bosshard (2005, p.22) memorably layers a further trope on the basic metaphor as to indicate the ability of accountability through transparency to bring about change for the good. His claim that 'Sunshine is the best disinfectant' elegantly captures the cleansing potential of a regime of transparency, without yet explaining quite how that might work.

\section{Types of transparency}

Transparency is a concept that is applied at all possible levels from international organisations, states, private corporations, civil society organisations, individuals and groups of individuals. Regulations for transparency abound at all these levels and the technology by which transparency can be enforced is hard to avoid. States can no long easily conceal the movements of their armed forces or offer misleading estimates of their agricultural output when remote sensing from satellites records and passes on revealing data whether they like it or not. Likewise, individuals have their movements observed by closed circuit TV and their messages technologically monitored with greatly increasing frequency. In fact, some accounts of transparency merely equate it with the density and speed of transmission of sensing devices

It is possible to distinguish a number of levels at which the word is generally used in this broad 
sense. The main levels or types of transparency are as follows:

1. The adoption of openness in public and private sector governance. This encompasses a broad view of what transparency means, including both a mentality and a system or set of systems. A state's own disclosure structures are sometimes referred to as domestic transparency. They are essentially directed towards permitting broad public knowledge of the actions of those who hold power, but also for purposes of crime detection and law enforcement..

2. A more limited procedural transparency can be identified in some usage of the word. In this sense, the simple existence of a set of provisions for making public, or allowing access to, details of the functioning of some or all of the activities of an organisation, is referred to as transparency.

3. Radical transparency, which is a management method by which almost all the decision making in an organisation is carried out publicly. The exceptions to transparency in such a system are matters such as personal privacy or the security of systems. It is regarded as more appropriate in working environments based on the Internet or intranets that do not suffer from the potential for the transmission of errors inherent in oral communication. It connects directly with the open source movement, which embodies the spirit of radical transparency.

4. The potential for a kind of systemic or total transparency in which the actions of absolutely everyone are exposed to the eye of interested parties. This idea is based on the existing capacity for deep surveillance that can provide detail about the life of anyone, in the interests of effective administration and policing, and to the private sector, for purposes of more accurately targeted business activity, to the state itself so that its policy can be monitored internationally. It is sometimes referred to as imposed transparency. It is the nightmare transparency of Orwell's Nineteen Eighty Four.

Although the meanings of transparency set out above undoubtedly have some negative connotations, it is chiefly used in a strongly positive way.

\section{Related terms}

There are a number of words that are regularly associated with transparency or are used in ways that share some of the meaning of the term. It is worth identifying the main ones here. They can be grouped according to what Oliver (2004) identifies as the three elements in transparency: the observed, the observer and the means or method of observation.

Broadly speaking, the observed include government, the corporate sector, and also those responsible for the dissemination of knowledge, who might be referred to as the knowledge sector.

A driving principle behind transparency in the public sphere is open government - a concept that sets the context for transparency in the sphere of governance. Systems of open government will usually include facilities for observation of official meetings by members of the public, public consultation processes for planning and decision-making, and statutory rights of access by the public to official information, usually expressed in freedom of information laws. Open government is also furthered by regulatory systems - the state's favoured method of intervening in both the business and public service provision environments in the latter part of the twentieth century.

These form part of what is sometimes termed a national integrity system: a set of institutions and procedures that offers to check corruption its various forms. A national integrity system includes at the most basic level the institutions of a democratically elected legislature, an executive answerable both to the legislative body and to an independent judiciary. More than this, however, it should also include a supreme audit institution, regulatory bodies, ombudsmen, and independent anticorruption agencies.

The private sector is observed because of the need for business integrity and corporate social responsibility, which represents an ethical and accountable approach to corporate governance. Corporations that embrace the concept monitor and offer up for audit their social performance, environmental impacts, employee relations and a range of other ethically sensitive aspects of business. Formal reporting of non-financial matters complements the financial accounting already required by national laws and international agreements. This reporting is usually on an annual basis, and is often verified by independent and external third parties. It represents 
a considerable contribution to corporate transparency.

The knowledge sector includes the press and media, the ethical standards of which are crucial to effective transparency. Scholarly integrity and publishing and broadcasting standards are also highly important. There is also, however, the open access movement to take into account. Open access, open archives and open source are ways of referring to aspects of a movement that challenges the dominant modes of defining intellectual property, with their associated financial and other restrictions on the use of information. Open access encourages the creators of intellectual property, particularly that which is based on publicly-funded work, to make the documentation freely available to readers, probably through electronic open archives, rather than distribute it through conventionally published books and journals. Open source counters the control of software as intellectual property arguing that it should be seen as a common resource with its code available to all for them to customise, modify and improve as best they can. Open access can be seen as a substantial contribution to a transparent research and development environment.

We can think of the observer or observers, as members of Civil Society - unfortunately as yet an imprecisely defined term. Although it may seem to refer to society as a whole it is generally used to refer to the non-governmental organisations (NGOs) and networks and the social movements that they represent. Civil society is a distinct third element alongside the long-accepted public sector - private sector duality. Unfortunately the clarity of this is muddied in some countries by the lumping together of the non-governmental sector and the private sector as civil society. Civil society organisations are the chief source of pressure for openness and accountability in both public and private sectors throughout the world. The observer is also anyone who works with information, whether they regard themselves as socially involved and aware and involved or not.

As for the methods of observation, terms that apply include the following

Audit describes, in the first place, the sets of legal requirements by which society monitors the honesty and efficiency of financial dealing by those who handle money and other resources on behalf of others. The requirement to submit publicly available and independently audited accounts is one side of the bargain by which the state offers various forms of legal protection for business activity in exchange for openness on the part of the company or other organisation. The association of the term with financial matters is not an accident as probably the longest-established systems of accountability are the sets of procedures to monitor the legality of public and private financial transactions. However, the term audit is now not solely attached to financial matters, and there are various other forms of audit that allow the examination of many aspects of public and corporate life.

Scrutiny -This is often used as yet another general term for the citizen's use of transparency to know more about the workings of government. It has more recently become used in a more specific sense referring to systems by which government and local government representatives can be subject to public questioning.

Disclosure - disclosure is both a general term for opening up to transparency, and also a specific process in legal practice (sometimes referred to as full disclosure) where the evidence for each party in a case before the courts is made open to the other. Freedom of information laws provide formal disclosure procedures in the public sector. Disclosure is particularly significant when it is carried out in the public interest against the will of those whose concealment is broken. This public interest disclosure is usually known as whistleblowing.

\section{Conclusion}

A better understanding of the concept of transparency and a recognition that part, at least, of the work of any information professional can be identified as contributing to transparency is a major step forward in the creation of a well-governed and corruption-free world. Those who work with information, whether they be journalists, writers, editors, publishers, booksellers, Internet service and content providers, web designers, database managers, records managers, archivists or librarians, are not merely observers, but also agents of transparency. Some of these professions consciously see themselves in this way. Others more normally regard their work in terms of the neutral provision of facilities and content. A better understanding of transparency brings with it the recognition that whether we intended it or not, and whether we like it or not, we take on responsibilities to society when we remove any of the layers of concealment in which corruption and misgovernment thrive. Transparency is not merely an absence. It is an indispensable 
requirement for good governance that needs capable professionals to ensure its presence, continuance and effective use.

\section{References}

Bosshard, P. (2005) The environment at risk from monuments of corruption. In: Transparency International, Global Corruption Report 2005. London: Pluto Press. Pp. 19-23.

Brin, D. (1998) The transparent society: will technology force us to choose between privacy and freedom? Reading, Mass: Addison-Wesley.

Clay, E. (2004) Kenya's government is full of corrupt gluttons. Independent [London], $16^{\text {th }}$ July p.27.

Cox, R. (2006) Ethics, accountability and recordkeeping in a dangerous world. London: Facet Publishing.

Florini, A. (2000) The end of secrecy. In: Finel, B. and Lord, $K$. Power and conflict in the ago of transparency. Basingstoke: Palgrave. Pp.13-28.

Oliver, R.W. (2004) What is transparency? New York: McGraw-Hill.

Rice, X. (2006) Our man in Africa: lovely people, but it's just a pity you're corrupt from head to toe. Guardian [London] $11^{\text {th }}$ November, p.3.

Transparency International (2006) Frequently asked questions about corruption. Available at http://www. transparency.org/news room/faq/co rruption faq [Accessed 21.12.2006]. 